\title{
Case Report: A Case of X-Linked Agammaglobulinemia With High Serum IgE Levels and Allergic Rhinitis
}

\section{OPEN ACCESS}

Edited by:

Sergio Rosenzweig, National Institutes of Health $(\mathrm{NIH})$, United States

Reviewed by: Joshua Milner, National Institutes of Health (NIH) United States Tadashi Ariga,

Hokkaido University, Japan

*Correspondence: Bianca Cinicola biancacinicola@gmail.com

${ }^{+}$These authors have contributed equally to this work and share senior authorship

Specialty section: This article was submitted to Primary Immunodeficiencies, a section of the journal

Frontiers in Immunology

Received: 11 July 2020 Accepted: 06 October 2020 Published: 05 November 2020

Citation:

Cinicola B, Uva A, Leonardi L, Moratto D, Giliani S, Carsetti R, Ferrari S, Zicari AM and Duse $M$ (2020) A Case of X-Linked Agammaglobulinemia With High Serum IgE Levels and Allergic Rhinitis.

Front. Immunol. 11:582376. doi: 10.3389/fimmu.2020.582376

\begin{abstract}
Bianca Cinicola ${ }^{1 *}$, Andrea Uva ${ }^{1}$, Lucia Leonardi ${ }^{1}$, Daniele Moratto ${ }^{2,3}$, Silvia Giliani ${ }^{2,4}$, Rita Carsetti ${ }^{5}$, Simona Ferrari ${ }^{6}$, Anna Maria Zicari ${ }^{1+}$ and Marzia Duse ${ }^{1 \dagger}$

${ }^{1}$ Department of Pediatrics, Policlinico Umberto I, Sapienza University of Rome, Rome, Italy, ${ }^{2}$ Cytogenetic and Medical Genetics Unit, "A. Nocivelli" Institute for Molecular Medicine Spedali Civili Hospital, Brescia, Italy, ${ }^{3}$ Flow Cytometry Unit, Clinical Chemistry Laboratory, Spedali Civili Hospital, Brescia, Italy, ${ }^{4}$ Department of Molecular and Translational Medicine, University of Brescia, Brescia, Italy, ${ }^{5}$ B Cell Physiopathology Unit, Immunology Research Area, Bambino Gesù Children Hospital, Rome, Italy, ${ }^{6}$ Medical Genetics Unit, S. Orsola-Malpighi University Hospital, Bologna, Italy
\end{abstract}

X-linked Agammaglobulinemia $(X L A)$ is a rare genetic disorder of $B$-lymphocyte differentiation, characterized by the absence or paucity of circulating B cells, markedly reduced levels of all serum immunoglobulin isotypes and lack of specific antibody production. Bruton Tyrosine Kinase (BTK) gene encodes a cytoplasmic tyrosine kinase involved in the $B$ cell maturation and its mutation, blocking $B$ cell differentiation at the pre-B cell stage, and is responsible for XLA. All domains may be affected by the mutation, and the many genotypes are associated with a wide range of clinical presentations. Little is known about genotype-phenotype correlation in this disorder, and factors influencing the phenotype of XLA are not clearly understood. In this report we present a unique case of a young patient affected by XLA. The disease was genetically diagnosed at birth due to a family history of XLA, but during follow up, it was characterized by a CD19+ B cell percentage consistently greater than $2 \%$. He never suffered severe infections, but at two years of age, he developed persistent rhinitis. Thus, total serum IgE levels were measured and detected over the normal range, and specific allergic investigations showed sensitization to dust mites. Further immunological tests (BTK expression, functional "in vitro" B cell proliferation upon CpG stimulation, B cell subset analysis) explained these findings as possible manifestations of a mild XLA phenotype. XLA patients rarely present with allergic manifestations, which could warrant further investigation. High serum lgE levels could be a sign of a mild phenotype, but their role and the mechanisms underlying their production in XLA need to be clarified.

Keywords: X-linked Agammaglobulinemia, BTK gene, protein expression, mild phenotype, IgE production, allergy 


\section{INTRODUCTION}

X-linked Agammaglobulinemia (XLA) is a primary immunodeficiency disease caused by a mutation in the Bruton Tyrosine Kinase $(B T K)$ gene that encodes an essential protein involved in B-cell maturation. In particular, it promotes preB cell expansion at the preB1 to preB2 stage $(1,2)$. The BTK gene is located in the Xq22 region of the $\mathrm{X}$ chromosome and has five distinct structural domains: Pleckstrin homology $(\mathrm{PH}), \mathrm{Tec}$ homology (TH), Src homology (SH3), SH2, and catalytic kinase (SH1) domains. All domains may be affected by mutations. Among all the XLA causative mutations, $15 \%$ to $20 \%$ are known to occur de novo (3). Carrier mothers are usually healthy, even if there is evidence of XLA syndrome in females due to skewed Xchromosome inactivation (4).

Failure of B-cell development caused by a BTK gene mutation in affected males leads to reduced levels of peripheral mature B lymphocytes, plasma cells and all immunoglobulin (Ig) isotypes (5). As a consequence, XLA patients are more susceptible to recurrent respiratory infections, mostly due to encapsulated pyogenic bacteria, and bowel infections caused by Salmonella, Yersinia, Campylobacter and Giardia (6). Therapy mostly consists of Ig replacement, with intravenous (IVIG), subcutaneous (SCIG), or enzyme facilitated immunoglobulin (7).

A definitive diagnosis of XLA is possible, based on the European Society for Immunodeficiencies (ESID) criteria, in a male presenting with $\mathrm{CD}^{+} 9^{+} \mathrm{B}$ cells $<2 \%$ and a confirmed mutation in the BTK gene and/or an absent BTK protein expression, and/or a male family member of maternal lineage with CD19+ B cells $<2 \%$ (8).

Despite defined diagnostic criteria, a wide number of BTK mutations is associated with different clinical phenotypes, including several atypical or leaky XLA forms (9-11).

Different mutations in the BTK gene, classified according to their severity by Conley and Howard (12), may influence the severity of the disease (13) and result in a considerable heterogeneity in the clinical spectrum of XLA (14); however, genotype-phenotype correlation has not been clearly established (15).

Allergy can also occur in XLA patients. Both IgE mediated and non-IgE mediated symptoms have been reported. In particular, Melo et al. (16) described a patient with XLA and non IgE mediated cow milk protein allergy. Besides, IgE mediated allergy have been reported in two different studies $(17,18)$ describing two XLA patients with a severe course of disease, low serum immunoglobulin isotypes except for normal IgE levels, and hypersensitivity to several allergens. Recently, another study (19) identified an atypical case of XLA diagnosed at the age of 45 , characterized by CD19+ B cells $1 \%$, mild hypogammaglobulinemia and detection of serum $\operatorname{IgE}$ and allergen-specific IgE for cedar pollen and alternaria.

Finally, Kaneko et al. (20) reported high serum IgE levels in a mild XLA patient presenting with sensitization to dust mites and partial BTK expression on lymphocytes. Interesting, the authors assumed IgE levels as a critical marker for the detection of the leaky phenotype.

However, to the best of our knowledge, none of the studies on allergic XLA patients reported detailed immunological assessment.
Our study describes a unique case of a patient affected by XLA characterized by CD19+ B cells $>2 \%$ and allergic disease, with high serum IgE levels, persistent rhinitis and sensitization to dust mites.

Moreover, we performed a complete B cells subset analysis and a functional test on B lymphocytes along with BTK expression measurement, in order to better characterize his phenotype.

\section{CASE PRESENTATION}

We report the case of a 10-year-old boy admitted to our primary immunodeficiency disease (PID) outpatient service at three months of age with a diagnosis of XLA. The molecular test was performed at birth due to a positive family history (maternal uncle), identifying the presence of the BTK mutation (c.82C > T:p.Arg28Cys).

In the first three months of life, the patient was in a good physical condition; he never suffered severe infections and his growth was at the $75^{\text {th }}$ percentile. His first blood test showed a normal white blood cell (WBC) count (5.400 lymphocytes $/ \mathrm{mm}^{3}$ ), a CD19+ B cell percentage of $6 \%$ and reduced serum Ig levels: IgG $430 \mathrm{mg} / \mathrm{dl}$ (presumably mostly due to trans placental passage), IgA $<1 \mathrm{mg} / \mathrm{dl}, \operatorname{IgM}<1 \mathrm{mg} / \mathrm{dl}$ and $\operatorname{IgE} 4 \mathrm{mg} / \mathrm{dl}$. Immunoglobulin replacement (400 $\mathrm{mg} / \mathrm{kg}$ every 21 days) was started one month later to prevent severe infections. At two years of age, he converted to subcutaneous immunoglobulin therapy (SCIG) and, from the age of eight, he started hyaluronidasefacilitated SCIG.

Although the patient has never presented with severe infections, he developed persistent rhinitis at two years of age, successfully treated with antihistamines and topical corticosteroid. Despite the deficit of Ig production, total serum IgE levels were above the normal range $(246 \mathrm{mg} / \mathrm{dl})$, with normal levels of eosinophils in peripheral blood. Subsequently, serum IgE levels were persistently elevated with a maximum of $936 \mathrm{mg} /$ $\mathrm{dl}$ at the age of eight, and were always associated with normal eosinophil counts. Considering a possible atopic condition, skin prick test (SPT) was performed highlighting sensitization to dust mites, confirmed by allergen-specific IgE levels to dermatophagoides pteronyssinus (DPT) $(\mathrm{IgE}=2,44 \mathrm{kU} / \mathrm{L})$.

Evaluation of lymphocytes over the years demonstrated a $\mathrm{CD} 19+\mathrm{B}$ cell percentage consistently greater than $2 \%$ (range, $2-$ $7 \%)$ with absolute counts of at least 43 cells/ $\mu$ l. Functional "in vitro" analysis of B lymphocytes, upon response to $\mathrm{CpG}$ stimulation, showed a mild proliferative ability and impaired plasma cell differentiation coupled with the absence of IgA class antibodies in the supernatants, but detectable IgM and IgG levels. To determine if clinical and laboratory findings of the patient (including elevated total IgE serum levels) could be explained by a mild XLA phenotype, BTK expression was measured by an indirect flow cytometric test performed after staining blood cells with a commercial anti-BTK monoclonal antibody (Becton Dickinson), followed by incubation with a secondary PEconjugated antibody (southern Biotech). Flow cytometry analysis displayed the presence of a residual BTK protein 
expression of both patient's B lymphocytes (Figure 1) and myeloid lineage cells (monocytes and granulocytes). To note, BTK was identified as a single peak for each population, with a Mean Fluorescence Intensity (MFI) corresponding respectively to approximately $40 \%$ (Figure 1) and 70\% (data not shown) of the values measured on the healthy control cells. Conversely, BTK was absent in circulating B lymphocytes of a patient diagnosed with a severe form of XLA, whose MFI was comparable to one of those lymphocyte subsets which intrinsically lack BTK expression, such as T cells (Figure 1).

Evaluation of peripheral B lymphocytes by flow cytometry demonstrated the presence of a normal distribution of CD20+ cell subsets. Percentages of cells having the phenotypical characteristics of recent bone marrow emigrants (RBE) (CD20+CD38++CD10+) and naïve cells (IgD+IgM+CD27-), as well as switched and unswitched memory cells (IgD-IgM$\mathrm{CD} 27+$ and $\operatorname{IgD}+\mathrm{IgM}+\mathrm{CD} 27+$ respectively), did not significantly differ from values observed in healthy agematched individuals, while only immunoglobulin-secreting cells (ISC) $(\mathrm{CD} 38+++\mathrm{CD} 27++\mathrm{CD} 20-)$ were below the normal range (Figure 2, central column). On the opposite, peripheral B cells of XLA patients with severe clinical manifestations and undetectable BTK expression did not display any ability to differentiate into mature cells (Figure 2, right column).

\section{DISCUSSION}

BTK gene mutations are collected in the BTKbase, which is an XLA-mutation registry established in 1994 (21). This database reports the distribution as well as the frequency of the different mutations in the protein domains.
So far, a total of 620 mutations in 974 unrelated families have been recorded (22), with heterogeneous XLA clinical presentations, which are often associated to the same mutation, making a genotype-phenotype correlation challenging to define among XLA patients, even in studies including a high number of patients (23). However, some studies showed that mild mutations, defined as mutations that may allow a residual protein function, could be linked to late-onset of disease, lower number of hospitalizations and severe infections before diagnosis, as well as higher Ig levels at diagnosis (24-27). These studies included patients carrying a missense mutation in the $\mathrm{PH}$ domain that involved the $\mathrm{R} 28 \mathrm{C}$ residue (Table 1) and presented with a milder disease despite very low circulating $\mathrm{B}$ cells (lower than 2\%) and low serum Ig levels. On the contrary, another study described a patient with the same amino acid substitution as our patient, but with a severe clinical phenotype characterized by several infections since 12 months of age (28). Thus, it is quite difficult to predict the clinical evolution of XLA patients based only on BTK gene analysis. It is possible that other factors, including epigenetic variables, could influence the course of the disease (29).

However, BTK gene analysis combined with study of protein expression might help in predicting the clinical phenotypes. Therefore, to better elucidate the genotype-phenotype correlation, two of the previously described studies analyzed BTK expression, which was found to be positive in some patients with amino acid substitutions, including R28C. At the same time, other mild mutations resulted in the absence of BTK protein in the cells analysed $(24,25)$. These results suggest that a milder disease could be explained by some residual function of the mutated protein, but the correlation between genotype, phenotype and protein expression is not clear yet, and further studies are needed to clarify this aspect.

\section{Severe XLA}

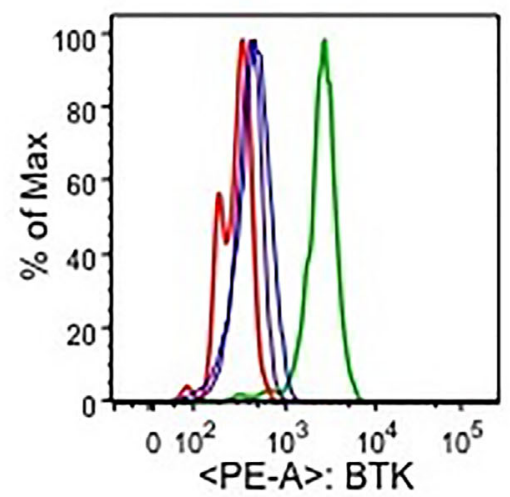

\section{Index patient}

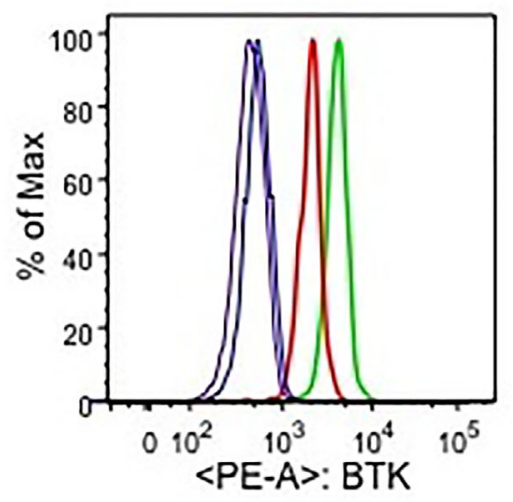

FIGURE 1 | Flow cytometric analysis of BTK expression in a severe XLA patient (left plot) and the index patient (right plot). For each plot, histograms representing BTK expression measured as Mean Fluorescence Intensity (MFI) are presented for the following cell subsets: B lymphocytes of a healthy control (green line), patient's B lymphocytes (red line), T lymphocytes of a healthy control (blue line), patient's T lymphocytes (purple line). 


\section{Healthy control Index patient Severe XLA}
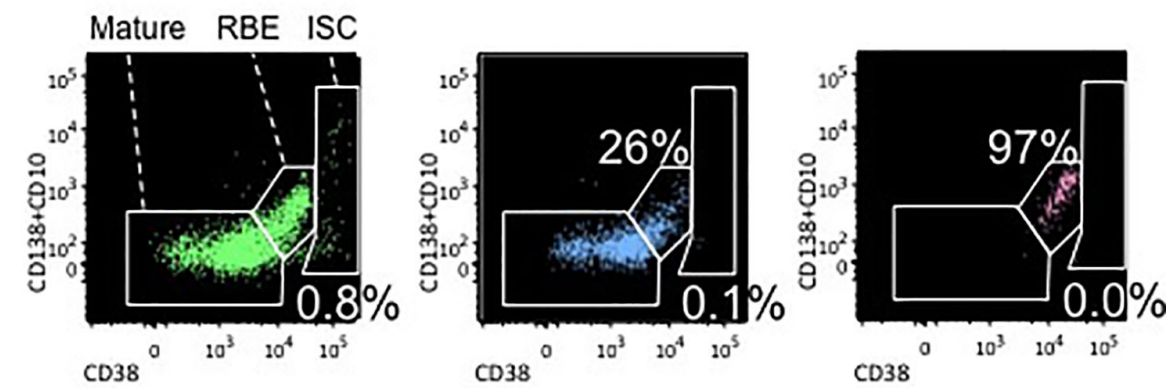

Mature RBE ISC
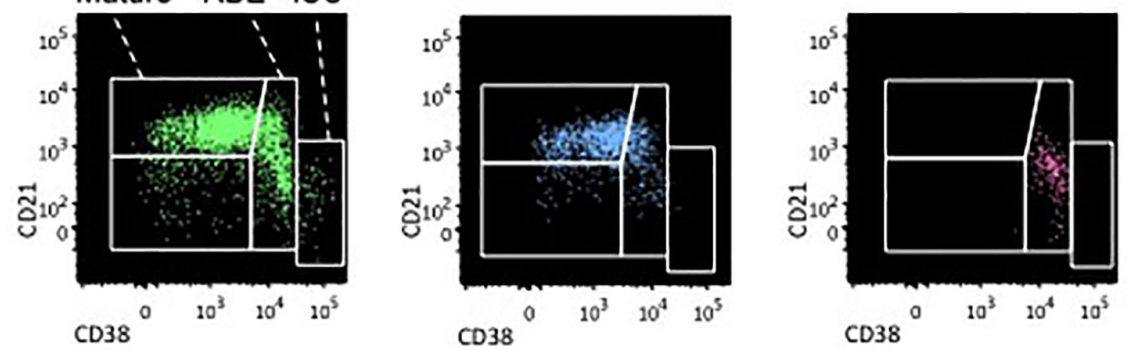

Switched memory $\operatorname{lgM}$ memory
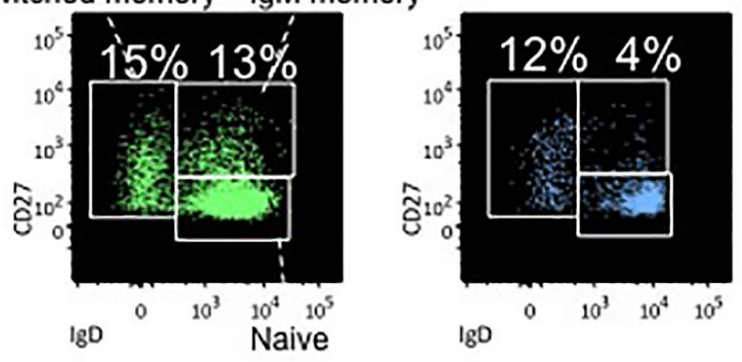

FIGURE 2 | Analysis of peripheral B cell subset distribution a healthy control (left column), the index patient (central column), and a severe XLA patient (right column). For each subject the following B cell subsets are presented: recent bone marrow emigrants (RBE) (CD20+CD38++CD10+), immunoglobulin-secreting cells (ISC) (CD38+++CD27++CD20-) and mature cells (CD20+CD38+/-CD10-) which are further classified in naïve cells (IgD+lgM+CD27-) and both switched memory (lgD-lgM$\mathrm{CD} 27+)$ and unswitched memory cells (lgD+lgM+CD27+).

TABLE 1 | Immunologic features and BTK expression in XLA patients with R28C substitution reported in literature.

\begin{tabular}{|c|c|c|c|c|c|c|c|c|}
\hline Author & Nucleotide Change & Amino Acid Substitution & $\operatorname{lgG}(\mathrm{mg} / \mathrm{dl})$ & $\lg A$ (mg/dl) & $\operatorname{lgM}(\mathrm{mg} / \mathrm{dl})$ & CD19 (\%) & BTK Protein & Phenotype \\
\hline (24) & $46278 \mathrm{C}>\mathrm{T}$ & $\mathrm{R} 28 \mathrm{C}$ & 410 & 53 & 16 & 1 & Expressed & Mild \\
\hline (25) & NA & $\mathrm{R} 28 \mathrm{C}$ & NA & NA & NA & NA & Expressed & Mild \\
\hline (26) & $214 \mathrm{C}>\mathrm{T}$ & $\mathrm{R} 28 \mathrm{C}$ & 267 & $<0.1$ & $<0.1$ & 0.1 & NP & Mild \\
\hline$(27)$ & $214 C>T$ & $\mathrm{R} 28 \mathrm{C}$ & 267 & $<10$ & $<10$ & 0.1 & NP & Mild \\
\hline (28) & $214 C>T$ & $\mathrm{R} 28 \mathrm{C}$ & 30 & 5 & 5 & 0.1 & NP & Severe \\
\hline
\end{tabular}

NP not performed NA not reported.

Our patient displayed typical clinical and immunophenotypical characteristics of subjects harboring permissive mutations. Number and severity of clinical manifestations correlate with the presence of three different leukocyte subsets expressing a reduced amount of BTK protein, as measured as a single fluorescence peak in a flow cytometric test. These are characteristics compatible with a mutation with residual protein expression but not with the presence of cells carrying one or more reversions of the original mutation. In fact, although revertant cells are not so uncommon in primary immunodeficiency diseases (30), they are limited to highly differentiated cells of those leukocyte subsets for which the reversion confers the most selective advantage (Moratto D. and Giliani S. unpublished data on Wiskott-Aldrich Syndrome and X-linked severe combined immunodeficiency revertant patients). Moreover, the high percentages of RBE and naïve cells are also in contrast with the hypothesis of a selection of revertant clones, and suggest the 
presence of B cells with a polyclonal repertoire, although a specific test to evaluate the clonality of the index patient's B cells was not performed.

In contrast to our findings, none of the above mentioned studies reported information on serum IgE levels and allergic symptoms in the XLA patients described. Indeed, typical XLA patients have no serum IgE. To the best of our knowledge, among XLA patients with R28C substitution, our patient seems to be the first subject with high serum IgE levels and sensitization to dust mites. Kaneko et al. (20) assumed that elevated IgE levels could be the critical marker in diagnosing mild XLA. They reported a patient carrying a different mutation (IVS11 $+3 \mathrm{G}>\mathrm{T}$ mutation on SH2 domain), leading to 80-bp truncated band and normal size BTK gene transcripts. This patient had detectable CD19+B cells $(2.1 \%)$, measurable IgG, IgM and IgA, elevated IgE levels (269 IU/ml) and allergen-specific IgE for house dust and mites. B cells could then proliferate due to antigen stimulation and differentiate into memory B cells, as in the case of our patient. Moreover, 31\% of CD19+ B cells (but not monocytes) expressed normal BTK protein.

The reason for high IgE serum levels is still not clearly understood. Two studies drive hypothesis on the IgE production in XLA patients.

Nonoyama et al. (31) analyzed four XLA patients with missense mutations, and one without a genetic diagnosis, characterized by circulating CD19+B cell levels $<1 \%$ and lack of BTK protein expression. After stimulation with anti-CD40 and IL-4, B-lymphocytes proliferated and produced quantities of IgE almost comparable to the controls (patient IgE not detectable prior to stimulation). This study speculates that "leaky" B cells from XLA patients could differentiate using BTK-independent pathways, such as a CD40-controlled pathway.

Another study (32) reported the case of a 7-year-old boy with XLA (Del E407 in the TH domain), who presented at diagnosis with $\mathrm{CD} 19+\mathrm{B}$ cells $<1 \%$, low expression $(0.70 \%)$ of BTK in monocytes, and low Ig levels of all isotypes, including IgE, but a positive sensitization to various inhalant allergens and allergic symptoms since the age of one. The authors supposed bias towards a $\mathrm{T}$ helper 2 pattern, since cytokines secreted by $\mathrm{T}$ lymphocytes in response to allergic stimuli can determine

\section{REFERENCES}

1. Vetrie D, Vořechovský I, Sideras P, Holland J, Davies A, Flinter F, et al. The gene involved in X-linked agammaglobulinaemia is a member of the Src family of protein-tyrosine kinases. 1993. J Immunol (2012) 188:2948-55.

2. Conley ME. Early defects in B cell development. Curr Opin Allergy Clin Immunol (2002) 2:517-22. doi: 10.1097/00130832-200212000-00007

3. Winkelstein JA, Marino MC, Lederman HM, Jones SM, Sullivan K, Burks AW, et al. X-linked agammaglobulinemia: report on a United States registry of 201 patients. Med (Baltimore) (2006) 85:193-202. doi: 10.1097/ 01.md.0000229482.27398.ad

4. Takada H, Kanegane H, Nomura A, Yamamoto K, Ihara K, Takahashi Y, et al. Female agammaglobulinemia due to the Bruton tyrosine kinase deficiency caused by extremely skewed X-chromosome inactivation. Blood (2004) 103:185-7. doi: 10.1182/blood-2003-06-1964 induction and maintenance of allergic inflammation, but further studies on the T cells of XLA patients are required to establish the pathophysiology of that process.

In conclusion, $\mathrm{X}$-linked Agammaglobulinemia is an immune disorder that manifests as different clinical phenotypes, from severe to a milder course of the disease. Much of the debate has been focused on the possible relationship between mutations in the $B T K$ gene and clinical phenotypes, with inconclusive results. As high serum IgE levels have been detected in XLA patients and their role and importance are still in the spotlight, all patients with mild mutations should be studied further in order to clarify the role of IgE production in influencing the severity of the disease and its prognostic significance.

\section{DATA AVAILABILITY STATEMENT}

The raw data supporting the conclusions of this article will be made available by the authors, without undue reservation.

\section{ETHICS STATEMENT}

Written informed consent was obtained from the minor's legal guardian for the publication of any potentially identifiable images or data included in this article.

\section{AUTHOR CONTRIBUTIONS}

All people who meet authorship ICMJE criteria are listed as authors, and all authors certify that they have participated equally in the work to take public responsibility for the content, including participation in the concept, design, analysis, writing, or revision of the manuscript. Furthermore each author certifies that this material or similar material has not been and will not be submitted to or published in any other publication. All authors contributed to the article and approved the submitted version.

5. Ochs HD, Smith CI. X-linked agammaglobulinemia. A clinical and molecular analysis. Med (Baltimore) (1996) 75:287-99. doi: 10.1097/00005792199611000-00001

6. Lederman HM, Winkelstein JA. X-linked agammaglobulinemia: an analysis of 96 patients. Med (Baltimore) (1985) 64:145-56. doi: 10.1097/00005792198505000-00001

7. Shillitoe BMJ, Gennery AR. An update on X-Linked agammaglobulinaemia: clinical manifestations and management. Curr Opin Allergy Clin Immunol (2019) 19:571-7. doi: 10.1097/ACI.0000000000000584

8. ESID - European Society for Immunodeficiencies. Available at: https://esid. org/Education/Diagnostic-Criteria-PID (Accessed September 15, 2020).

9. Carrillo-Tapia E, García-García E, Herrera-González NE, YamazakiNakashimada MA, Staines-Boone AT, Segura-Mendez NH, et al. Delayed diagnosis in $\mathrm{X}$-linked agammaglobulinemia and its relationship to the occurrence of mutations in BTK non-kinase domains. Expert Rev Clin Immunol (2018) 14:83-93. doi: 10.1080/1744666X.2018.1413349 
10. Sigmon JR, Kasasbeh E, Krishnaswamy G. X-linked agammaglobulinemia diagnosed late in life: case report and review of the literature. Clin Mol Allergy (2008) 6:5. doi: 10.1186/1476-7961-6-5

11. Stewart DM, Lian L, Nelson DL. The clinical spectrum of Bruton's agammaglobulinemia. Curr Allergy Asthma Rep (2001) 1:558-65. doi: 10.1007/s11882-001-0065-8

12. Conley ME, Howard V. Clinical findings leading to the diagnosis of X-linked agammaglobulinemia. J Pediatr (2002) 141:566-71. doi: 10.1067/ mpd.2002.127711

13. Teimourian S, Nasseri S, Pouladi N, Yeganeh M, Aghamohammadi A. Genotypephenotype correlation in Bruton's tyrosine kinase deficiency. J Pediatr Hematol Oncol (2008) 30:679-83. doi: 10.1097/MPH.0b013e318180bb45

14. Gaspar HB, Ferrando M, Caragol I, Hernandez M, Bertran JM, De Gracia X, et al. Kinase mutant Btk results in atypical X-linked agammaglobulinaemia phenotype. Clin Exp Immunol (2000) 120:346-50. doi: 10.1046/j.13652249.2000.01230.x

15. Lougaris V, Soresina A, Baronio M, Montin D, Martino S, Signa S, et al. Longterm follow-up of 168 patients with X-linked agammaglobulinemia reveals increased morbidity and mortality. J Allergy Clin Immunol (2020) 146:429-37. doi: 10.1016/j.jaci.2020.03.001

16. Melo KM, Dantas E, De Moraes-Pinto MI, Condino-Neto A, Gonzalez IGS, Mallozi MC, et al. Primary Immunodeficiency May Be Misdiagnosed as Cow's Milk Allergy: Seven Cases Referred to a Tertiary Pediatric Hospital. ISRN Pediatr (2013) 2013:470286. doi: 10.1155/2013/470286

17. Gajl-Peczalska KJ, Ballow M, Hansen JA, Good RA. IgE-bearing lymphocytes and atopy in a patient with X-linked infantile agammaglobulinaemia. Lancet (1973) 1:1254. doi: 10.1016/s0140-6736(73)90571-0

18. Ganier M, Lieberman P. Infantile agammaglobulinemia and immediate hypersensitivity to penicillin G. JAMA (1977) 237:1852-3. doi: 10.1001/ jama.237.17.1852

19. Fujioka T, Kawashima H, Nishimata S, Ioi H, Takekuma K, Hoshika A, et al. Atypical case of X-linked agammaglobulinemia diagnosed at 45 years of age. Pediatr Int (2011) 53:611-2. doi: 10.1111/j.1442-200X.2011.03409.X

20. Kaneko H, Kawamoto N, Asano T, Mabuchi Y, Horikoshi H, Teramoto T, et al. Leaky phenotype of X-linked agammaglobulinaemia in a Japanese family. Clin Exp Immunol (2005) 140:520-3. doi: 10.1111/j.1365-2249.2005.02784.x

21. Väliaho J, Smith CIE, Vihinen M. BTKbase: the mutation database for Xlinked agammaglobulinemia. Hum Mutat (2006) 27:1209-17. doi: 10.1002/ humu. 20410

22. Chun J-K, Lee TJ, Song JW, Linton JA, Kim DS. Analysis of clinical presentations of Bruton disease: a review of 20 years of accumulated data from pediatric patients at Severance Hospital. Yonsei Med J (2008) 49:28-36. doi: $10.3349 /$ ymj.2008.49.1.28

23. Holinski-Feder E, Weiss M, Brandau O, Jedele KB, Nore B, Bäckesjö CM, et al. Mutation screening of the BTK gene in 56 families with X-linked agammaglobulinemia (XLA): 47 unique mutations without correlation to clinical course. Pediatrics (1998) 101:276-84. doi: 10.1542/peds.101.2.276

24. López-Granados E, Pérez de Diego R, Ferreira Cerdán A, Fontán Casariego G, García Rodríguez MC. A genotype-phenotype correlation study in a group of 54 patients with X-linked agammaglobulinemia. J Allergy Clin Immunol (2005) 116:690-7. doi: 10.1016/j.jaci.2005.04.043

25. Broides A, Yang W, Conley ME. Genotype/phenotype correlations in Xlinked agammaglobulinemia. Clin Immunol (2006) 118:195-200. doi: 10.1016/ j.clim.2005.10.007

26. Chen X-F, Wang W-F, Zhang Y-D, Zhao W, Wu J, Chen T-X. Clinical characteristics and genetic profiles of 174 patients with X-linked agammaglobulinemia: Report from Shanghai, China (2000-2015). Med (Baltimore) (2016) 95:e4544. doi: 10.1097/MD.0000000000004544

27. Lee PPW, Chen T-X, Jiang L-P, Chan K-W, Yang W, Lee B-W, et al. Clinical characteristics and genotype-phenotype correlation in 62 patients with $\mathrm{X}$ linked agammaglobulinemia. J Clin Immunol (2010) 30:121-31. doi: 10.1007/ s10875-009-9341-5

28. Aadam Z, Kechout N, Barakat A, Chan K-W, Ben-Ali M, Ben-Mustapha I, et al. X-Linked Agammagobulinemia in a Large Series of North African Patients: Frequency, Clinical Features and Novel BTK Mutations. J Clin Immunol (2016) 36:187-94. doi: 10.1007/s10875-016-0251-Z

29. Plebani A, Soresina A, Rondelli R, Amato GM, Azzari C, Cardinale F, et al. Clinical, immunological, and molecular analysis in a large cohort of patients with X-linked agammaglobulinemia: an Italian multicenter study. Clin Immunol (2002) 104:221-30. doi: 10.1006/clim.2002.5241

30. Wada T, Candotti F. Somatic mosaicism in primary immune deficiencies. Curr Opin Allergy Clin Immunol (2008) 8:510-4. doi: 10.1097/ ACI.0b013e328314b651

31. Nonoyama S, Tsukada S, Yamadori T, Miyawaki T, Jin YZ, Watanabe C, et al. Functional analysis of peripheral blood B cells in patients with X-linked agammaglobulinemia. J Immunol (1998) 161:3925-9.

32. Shabestari MS, Rezaei N. Asthma and allergic rhinitis in a patient with BTK deficiency. J Invest Allergol Clin Immunol (2008) 18:300-4.

Conflict of Interest: The authors declare that the research was conducted in the absence of any commercial or financial relationships that could be construed as a potential conflict of interest.

Copyright (C) 2020 Cinicola, Uva, Leonardi, Moratto, Giliani, Carsetti, Ferrari, Zicari and Duse. This is an open-access article distributed under the terms of the Creative Commons Attribution License (CC BY). The use, distribution or reproduction in other forums is permitted, provided the original author(s) and the copyright owner(s) are credited and that the original publication in this journal is cited, in accordance with accepted academic practice. No use, distribution or reproduction is permitted which does not comply with these terms. 